\title{
30. COMMISSION DES VITESSES RADIALES STELLAIRES
}

\author{
Président: M. J.S. Plaskett, Director of the Dominion A strophysical Observatory, \\ Victoria, B.C., Canada.
}

Membres: MM. Adams, W. W. Campbell, Frost, Hamy, Harper, Henroteau, Jones, Joy, Moore, Pearce, Salet, Sanford.

\section{GENERAL PROGRESS}

The four years that have elapsed since the last meeting of the International Astronomical Union have witnessed steady progress in the determination of radial velocities, principally at the Mt Wilson Observatory, Pasadena, Cal., the Lick Observatory, Mt Hamilton, Cal., the Yerkes Observatory, Williams Bay, Wis., the Dominion Astrophysical Observatory, Victoria, B.C., the Observatory of the University of Michigan, Ann Arbor, Mich., and the Simeis Observatory in Russia. It will be useful, for the members of the Commission, to give a short summary of the radial velocity work completed and in progress since the last meeting.

The radial velocity work at the $\mathrm{Mt}$ Wilson Observatory has included a wide range of objects and has been developing more and more in the direction of investigations on special classes of stars. The radial velocities of long period variables, including physical studies and differences in velocity between emission and absorption lines, have been essentially completed, although observations are being continued to fainter stars of spectral types Me and N. Observations of about roo Cepheid and RR Lyrae variables have been obtained, and the study of faint Cepheids is being continued and is of special interest, on account of the great distance of these objects, in its bearing on the rotation of the galaxy. Orbits have been determined for several spectroscopic binaries and eclipsing variables and this work is being continued. Observations of emission Class B stars and of the interstellar sodium lines in the high temperature stars are in progress and work in the yellow and red regions of stellar spectra by an efficient grating spectrograph promises results of importance. General radial velocities of the unobserved Boss stars, of faint stars with large proper motion and of the stars down to visual magnitude 9 in the Kapteyn areas are all well advanced. A new development in radial velocity work has been inaugurated by the high dispersion Coudé spectrograph which is to be used, among other purposes, for very accurate radial velocities and for studies of the relative velocities of different lines.

Since the completion of the great programme of the radial velocities of all stars brighter than $5.5 \mathrm{I}$ visual magnitude at the Lick Observatory in I928, the work has developed rather in the direction of studies of special groups of stars. The work at the Chile station was concluded by the publication of the radial velocities of $35 \mathrm{I}$ stars last year. These included 213 Class B stars south of $-30^{\circ}$ declination, and a new programme of Class B stars of visual magnitudes 5.5 to 9.5 between declinations $-10^{\circ}$ and $-30^{\circ}$ is in progress at the Lick Observatory. A programme calling for observations with one prism dispersion ( $70 \mathrm{~A}$ to the $\mathrm{mm}$.), of some $800 \mathrm{~F}$ to $\mathrm{M}$ stars of photographic magnitude 8.5 to 8.6 , fairly uniformly distributed over the sky, is about two-thirds completed. Observations of a number of spectroscopic binaries discovered at the Lick Observatory, which are of special interest or difficulty, are being carried on with the Mills 3-prism spectrograph. The radial velocities of some I5O stars in open clusters were obtained in the recent study of these clusters and are being investigated with reference to the galactic rotation for which they are especially valuable on account of their great distances, I000 to 4000 parsecs. 
A great deal of time has been spent on the preparation of a general catalogue of radial velocities which will be referred to more particularly elsewhere in the report.

The radial velocity work at the Yerkes Observatory has been continued along the lines previously followed but with special attention to the brighter Class A and B stars, and a catalogue of the radial velocities of 500 Class A stars was issued in I930. Work with fine grained plates and high dispersion has added many lines of several elements to those previously identified in spectra of Classes A and B. Special studies have been made of $\epsilon$ A urigae and of stars containing peculiar manganese lines and of others with chromium and europium lines. Plates have also been secured of the new list of standard stars and of certain spectroscopic binaries.

At Victoria the programme of $\mathrm{O}$ to $\mathrm{B}_{5}$ stars has been completed, radial velocities of 523 have been published, a general catalogue of the velocities of Ioro of these stars compiled and published, while observations of fainter members of these spectral subdivisions are being continued. As a result of the discussion of these velocities the rotation of the galaxy has been definitely confirmed, while an auxiliary research has determined the radial velocities and the absorption of the interstellar matter in the direction of $3 I_{4}$ of these stars and has shown that it is uniformly distributed and partakes in the galactic rotation. In conjunction with the determination of spectroscopic parallaxes, the radial velocities of nearly 800 Class A stars have been obtained, of which about 500 are new. Radial velocities from one low dispersion spectrum of about $400 \mathrm{Ko}$ to $\mathrm{K}_{5}$ stars between 7.0 and 7.5 visual magnitude and within $\pm 10^{\circ}$ of the galactic plane were obtained for testing the galactic rotation. About 20 spectroscopic orbits have been derived as well as some general spectroscopic work undertaken, including radial velocities, on the Wolf-Rayet, $\mathrm{P}$ Cygni and some Class $M$ variable stars.

General radial velocity determinations are not made at Ann Arbor, although there have been many special studies of the spectra of Class Be including the velocities of the emission and absorption lines and of the spectra of Cepheid variables, with reference particularly to differences of velocities for lines originating at different levels. Observations for the long period of Algol, and on $\lambda$ Tauri and $\delta$ Librae as well as on several spectroscopic binaries are in progress, and work on irregular and semi-regular variables is also under way. In addition, the radial velocities of some 300 H.R. stars, mostly between 6.0 and 6.5 vis. mag., have been completed at the Simeis Observatory and some scattered radial velocity observations have been made at other institutions, but they are in general not of sufficient importance to require individual mention.

\section{GENERAL CATALOGUE OF RADIAL VELOCITIES}

The need of a comprehensive catalogue of all published radial velocities has been generally felt among astronomers for some time. This need has been only partially met by J. Voûte in two catalogues of radial velocities, the last including about 4000 entries. These catalogues, however, contained no critical discussion of the various observations and the velocities could only be considered as provisional. Schlesinger's "Catalogue of Bright Stars" is limited to the H.R. stars, and contains, with other data, the radial velocities, reduced to the Lick system, of H.R. stars whose velocities had been published prior to June I930. These velocities are more homogeneous than Voûte's, but as the catalogue does not contain stars fainter than 6.5 visual magnitude, there are several hundred known velocities not included. 
Informal discussion among the members of the Commission had indicated not only the need of a comprehensive general catalogue of radial velocities which would unite all the scattered observations into one homogeneous system but also the desirability that this catalogue be prepared by an astronomer of sufficiently wide experience in this work to assign suitable weights and determine systematic corrections for the various observations. Consequently correspondence was initiated about the end of I928 between the chairman and Dr J. H. Moore, who expressed his readiness to undertake the preparation of a general catalogue of radial velocities and the willingness of the Lick Observatory to publish it. After a thorough discussion with Dr Moore, a circular letter was sent to each member of the Commission asking their opinions concerning the data desirable to be included and the general form of the catalogue.

The general agreement among the replies as to the main features desirable in such a catalogue was concretely embodied in a catalogue of the radial velocities of Ioro $\mathrm{O}$ and $\mathrm{B}$ type stars by Plaskett and Pearce which was then in preparation. With this material as a guide, and with these velocities, which were adopted unchanged, as a nucleus, Dr Moore fixed upon the final form and commenced the preparation of the general catalogue. From the catalogue which contains the radial velocities of 6739 stars members may realize the amount of labour involved and see the complete and authoritative character of the work. If nothing more had been accomplished by the Commission since its last meeting than its part in the initiation of this valuable catalogue, its existence would have been fully justified.

The large amount of work required in the compilation of the catalogue has, however, fallen mainly on one member of the Commission, Dr J. H. Moore. Consequently it is hoped that the Commission will suitably express and record its appreciation and that of astronomers generally to Dr Moore for the sacrifice of his time for research required in the preparation of the catalogue and to the Lick Observatory for meeting the costs of publication of this valuable contribution to astronomy.

\section{STANDARD VELOCITY STARS}

The list of standard velocity stars published in the last report has been of considerable service in providing checks on systematic errors of radial velocity determinations and in the provision of suitable stars for spectro-comparator standards or for the preparation of tables of wave-lengths. $\mathrm{Dr} \mathrm{J}$. A. Pearce has suggested, as the published list contains no stars of spectral Classes $O$ and $B$, that the stars in Table $I$ being stars of well determined radial velocities, taken from the recent catalogue of Plaskett and Pearce, be added to the previous list.

The need of additional standard stars of fainter magnitude has been expressed by Dr Redman, who experienced difficulty in finding the origin of an obscure systematic error appearing in low dispersion spectra of Class $K$ stars of $7 \cdot 0$ to 7.5 visual magnitude. A possible cause is the great difference in exposure times between the standards, of average magnitude $2 \cdot 2$, and the stars concerned which are 5 magnitudes fainter, a factor of IOO to $I$, and hence the desirability of obtaining fainter velocity standards. In response to this need transmitted by the chairman, Dr Adams has sent the list of dwarf stars in Table II with radial velocities obtained with low dispersion, and has offered to obtain observations with higher dispersion of these or other stars selected by the Commission. 


\section{TABLE I}

Recommended Standard Velocity Stars of Classes $O$ and $B$.

\begin{tabular}{|c|c|c|c|c|c|c|}
\hline Star & $\begin{array}{l}\text { No. } \\
\text { obs. }\end{array}$ & $\begin{array}{l}\text { Observa- } \\
\text { tion } \\
\text { period }\end{array}$ & $\begin{array}{l}\text { Mean } \\
\text { observed } \\
\text { velocity }\end{array}$ & $\mathbf{W t}$ & $\begin{array}{l}\text { Range of } \\
\text { observed } \\
\text { velocity }\end{array}$ & $\begin{array}{l}\text { Obser- } \\
\text { vatory }\end{array}$ \\
\hline $\begin{array}{l}\text { H.D. } 886 \\
\text { Peg. } \\
\text { 00 } 08^{\mathrm{n}} \cdot 1 \\
+14^{\circ} 38^{\prime}\end{array}$ & $\begin{array}{r}20 \\
11 \\
3\end{array}$ & $\begin{array}{l}1899-1911 \\
1901-1904 \\
1924-1925\end{array}$ & $\begin{array}{l}+4.9 \pm 0.5 \\
+5.0 \pm 0.7 \\
+6.5 \pm 0.3\end{array}$ & $\begin{array}{r}20 \\
11 \\
2\end{array}$ & $\begin{array}{l}+0.5 \text { to }+12 \cdot 1 \\
+3.1 \text { to }+9 \cdot 9 \\
+6.1 \text { to }+\mathbf{7 \cdot 3}\end{array}$ & $\begin{array}{l}\text { L, III } \\
\text { Y, III, I } \\
\text { V, I }\end{array}$ \\
\hline 2.87 B2ss & $\overline{34}$ & & $\overline{+5.0 \pm 0.5}$ & & & \\
\hline $\begin{array}{l}\text { H.D. } 3360 \\
\text { ל. Cas. } \\
00^{\mathrm{n}} 31^{\mathrm{m} \cdot 4} \\
+53^{\circ} 21^{\prime}\end{array}$ & $\begin{array}{l}7 \\
8 \\
3\end{array}$ & $\begin{array}{l}1901-1910 \\
1903-1924 \\
1924-1926\end{array}$ & $\begin{array}{l}+2.4 \pm 0.5 \\
+\quad 2.0 \pm 0.4 \\
+\quad 1.9 \pm 0.2 \\
\end{array}$ & $\begin{array}{r}10 \\
16 \\
3\end{array}$ & $\begin{array}{l}+0.1 \text { to }+3.9 \\
-1.5 \text { to }+3.2 \\
+1.3 \text { to }+2.2\end{array}$ & $\begin{array}{l}\text { X, III, I } \\
\text { L, III, I } \\
\text { V, I }\end{array}$ \\
\hline $3 \cdot 72$ B2sk & $\overline{18}$ & & $\overline{+2 \cdot 1 \pm 0 \cdot 3}$ & & & \\
\hline $\begin{array}{l}\text { H.D. } 34078 \\
\text { Boss } 1249 \\
5^{\mathrm{h}} 09^{\mathrm{m}} \cdot 7 \\
+34^{\circ} 12^{\prime} \\
5 \cdot 81 \text { o9ssk }\end{array}$ & $\begin{array}{l}6 \\
9 \\
1\end{array}$ & $\begin{array}{l}1911-1912 \\
1921-1922 \\
1924\end{array}$ & $\begin{array}{l}+60.0 \pm 1 \cdot 5 \\
+59 \cdot 0 \pm 0.8 \\
+57.8 \\
+59 \cdot 3 \pm 0.7\end{array}$ & $\begin{array}{l}6 \\
9 \\
1\end{array}$ & $\begin{array}{l}+53 \text { to }+64 \\
+54 \cdot 7 \text { to }+64 \cdot 8\end{array}$ & $\begin{array}{l}\text { W, I } \\
\text { V,I } \\
\text { Y, I }\end{array}$ \\
\hline $\begin{array}{c}\text { H.D. } 36591 \\
\text { Boss } 1343 \\
5^{\mathrm{h}} 27^{\mathrm{m} \cdot 7} \\
-01^{\circ} 40^{\prime} \\
5 \cdot 30 \text { B2sk }\end{array}$ & $\begin{array}{l}\mathbf{4} \\
\mathbf{5} \\
\mathbf{3}\end{array}$ & $\begin{array}{l}1917-1921 \\
1917-1924 \\
1924-1925\end{array}$ & $\begin{array}{l}+34 \cdot 5 \pm 0.7 \\
+34 \cdot 0 \pm 0.3 \\
+34 \cdot 5 \pm 0 \cdot 4 \\
+34 \cdot 3 \pm 0.3\end{array}$ & $\begin{array}{l}8 \\
5 \\
3\end{array}$ & $\begin{array}{l}+32 \cdot 2 \text { to }+37 \cdot 1 \\
+33 \cdot 1 \text { to }+35 \cdot 2 \\
+33 \cdot 6 \text { to }+37 \cdot 4\end{array}$ & $\begin{array}{l}\text { L, III, II } \\
\text { Y, I } \\
\text { V, I }\end{array}$ \\
\hline $\begin{array}{l}\text { H.D. } 37128 \\
\quad \begin{array}{l}\text { Ori } \\
5^{\mathrm{h}} 31^{\mathrm{m}} \cdot 1 \\
-01^{\circ} 16^{\prime} \\
1 \cdot 75 \mathrm{~B} 0 \mathrm{k}\end{array}\end{array}$ & $\begin{array}{l}18 \\
67 \\
30\end{array}$ & $\begin{array}{l}1901-1909 \\
1902-1918 \\
1913-1914\end{array}$ & $\begin{array}{l}+28 \cdot 8 \pm 0 \cdot 7 \\
+25 \cdot 4 \pm 0 \cdot 1 \\
+25 \cdot 6 \pm 0 \cdot 6 \\
\\
+25 \cdot 8+0.2\end{array}$ & $\begin{array}{l}1 \\
6 \\
2\end{array}$ & $\begin{array}{l}+18 \cdot 3 \text { to }+36 \cdot 7 \\
+22 \cdot 5 \text { to }+28 \\
+15 \cdot 7 \text { to }+33 \cdot 5\end{array}$ & $\begin{array}{l}\text { Y, III, I } \\
\text { L, III, I } \\
\text { AA, I }\end{array}$ \\
\hline $\begin{array}{l}\text { H.D. } 160762 \\
\text { ¿Her. } \\
17^{\text {h }} 36^{\mathrm{m} \cdot 6} \cdot 6 \\
+46^{\circ} 04^{\prime} \\
3 \cdot 79 \mathrm{~B} 3 \mathrm{~s}\end{array}$ & $\begin{array}{r}14 \\
6 \\
11 \\
2 \\
\frac{2}{33}\end{array}$ & $\begin{array}{l}1901-1925 \\
1902-1911 \\
1920 \\
1923-1924\end{array}$ & $\begin{array}{l}-18 \cdot 0 \pm 0.7 \\
-18 \cdot 6 \pm 1.0 \\
-17.6 \pm 0.9 \\
-17.0 \\
-18.0 \pm 0.6\end{array}$ & $\begin{array}{r}11 \\
6 \\
3 \\
1\end{array}$ & $\begin{array}{l}-12 \cdot 9 \text { to }-27 \cdot 5 \\
-13 \cdot 7 \text { to }-25 \cdot 1 \\
-10 \cdot 4 \text { to }-25 \cdot 9 \\
-15 \cdot 0 \text { to }-18 \cdot 9\end{array}$ & $\begin{array}{l}\text { Y, III, I } \\
\text { L, III } \\
\text { O, I* } \\
\text { V, I }\end{array}$ \\
\hline $\begin{array}{l}\text { H.D. } 166182 \\
102 \mathrm{Her} \\
18^{\mathrm{h}} 04^{\mathrm{m} \cdot 4} \\
+20^{\circ} 48^{\prime} \\
4 \cdot 43 \mathrm{~B} 2 \mathrm{sk}\end{array}$ & $\begin{array}{r}9 \\
8 \\
9 \\
3 \\
29\end{array}$ & $\begin{array}{l}1902-1908 \\
1903-1911 \\
1916-1920 \\
1920-1925\end{array}$ & $\begin{array}{l}-13 \cdot 3 \pm 1 \cdot 2 \\
-13 \cdot 5 \pm 0 \cdot 5 \\
-13 \cdot 1 \pm 1 \cdot 4 \\
-13 \cdot 1 \pm 0 \cdot 6 \\
-13 \cdot 0 \pm 0 \cdot 5\end{array}$ & $\begin{array}{r}14 \\
16 \\
3 \\
3\end{array}$ & $\begin{array}{l}8.1 \text { to }-18.5 \\
-11.0 \text { to }-16.8 \\
-13.4 \text { to }-27.0 \\
-11.4 \text { to }-14.3\end{array}$ & $\begin{array}{l}\text { Y, III, I } \\
\text { L, III } \\
\text { O, I* } \\
\text { V, I }\end{array}$ \\
\hline
\end{tabular}

* A systematic correction of $+9.4 \mathrm{~km}$./sec. has been applied to the published velocity of Henroteau.

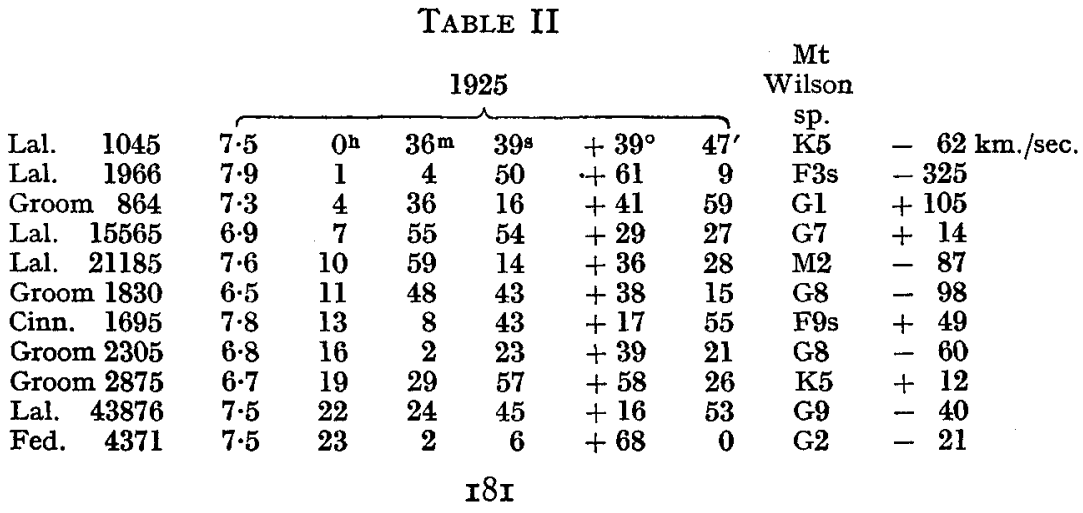


Dr Moore has also offered to co-operate in securing three-prism observations of stars brighter than photographic magnitude $7 \cdot 0$ and suggests that the list might include some 20 stars of visual magnitude $5^{\circ} 0$ to $7^{\circ}$. The Dominion Astrophysical Observatory will also be glad to co-operate in this useful work and it is suggested that the Commission appoint a sub-committee to prepare a list of suitable additions of fainter stars to the standard velocity stars and to arrange, if necessary, for accurate determinations of their radial velocity.

\section{RADIAL VELOCITIES IN THE SOUTHERN SKY}

The chairman wishes to direct the attention of the members of the Commission and through them of the International Astronomical Union to the urgent need of additional radial velocities in that portion of the sky that cannot be reached by the observatories now engaged in the determination of radial velocities. Since the last meeting of the Union, the Cape Observatory and the Chile Station of the Lick Observatory have both ceased radial velocity observations and few radial velocities south of declination $-30^{\circ}$ can now be obtained. The previously unbalanced condition of radial velocity observations, with one fourth of the sky only partially observed, will become increasingly accentuated and every effort should be made to remedy this condition, which militates against progress in many directions.

It is only necessary to point out that in many statistical investigations of stellar motions, the results are rendered incomplete and uncertain by the lack of radial velocities of the southern stars. The chairman may be pardoned for mentioning particularly the case of the high temperature stars where the need of southern velocities is particularly urgent. In the investigation of the solar motion, the galactic rotation and the $\mathrm{K}$ term for the Class $\mathrm{O}$ and $\mathrm{B}$ stars and of the motions and distribution of the interstellar diffuse matter as determined from the displacements of the interstellar calcium lines in these stars, there are effectively radial velocity observations over little more than half the galactic circle. It is impossible to be sure of the results of any discussion of such incomplete material and until the velocities are rounded out by similar data from the southern stars we can have no certain clue, for example, to the nature and producing cause of the mysterious $\mathrm{K}$ term so prominent a phenomenon in the Class $\mathrm{O}$ and $\mathrm{B}$ stars, nor can the other anomalies and peculiarities in the motions of these stars be explained.

The need for observations in other spectral classes is almost equally acute and, in addition, the rich field awaiting investigation in the Magellanic Clouds only needs to be mentioned to indicate the great advances that would undoubtedly result from the use of a large modern reflecting telescope in the southern hemisphere, even if only used for the determination of radial velocities. It was proposed to move the Radcliffe Observatory from Oxford to South Africa and to instal there a 72 -inch telescope with a suitable spectrograph for radial velocities and other spectroscopic work. Unfortunately, however, legal and other difficulties have intervened and the outcome is uncertain.

Your chairman, therefore, considers that the Commission and the Union could undertake no more useful work, nor one which promises greater advances in astronomy, than to use every possible influence in furthering plans for the estab- 
lishment and efficient operation of a large telescope or telescopes south of the equator and this purpose is earnestly commended to the careful consideration of the Commission.

\section{REPORTS OF SUB-COMMITTEES}

These reports indicate considerable progress not only in the work directly accomplished but in the clarifying of the situation generally in the two fields which the sub-committees were appointed to consider and investigate.

\section{(a) Report of Sub-Committee on Co-operation in Radial VELOCITY OBSERVATIONS}

The sub-committee, appointed for the purpose of considering "whether there should be co-operative plans for the systematic extension of radial velocity determinations to stars other and fainter than those hitherto observed," respectfully submit the following report:

Careful consideration has been given to the present status of radial velocity determinations, as shown by the published results for about 6700 stars and by information concerning observations now in progress, with a view to ascertaining whether a systematic programme of observation of the fainter stars, to be carried on by co-operation between several observatories, is desirable or practicable.

The situation with regard to stellar radial velocities may be summarized as follows: All stars brighter than visual magnitude 5.5I (2480), the Boss stars between 5.5 and 7.5 north of declination $-20^{\circ}$, as well as a number as faint as 8.0 have been observed for radial velocity. The data are published for practically all stars of Class $B\left(B_{0}-B_{5}\right)$ to magnitude 6.5 and for those north of $-\mathrm{Ir}^{\circ}$ to 7.5 , and observations are now being extended to the fainter members of this class north of $-30^{\circ}$. In addition, among the northern stars we possess fairly complete data for those of Classes $\mathrm{R}, \mathrm{N}$ and $\mathrm{Me}$ to magnitude 9.0 , for those with large proper motions to magnitude $9 \cdot 0$, and for a number of variables and others of special interest. Present programmes contemplate the observation of still fainter objects in these classes. Radial velocities will soon be available for about I I0o Class A stars, brighter than magnitude 6.5 , and for 800 stars of the later spectral classes between 7.5 and 8.5 , as well as for members of the open clusters to magnitude $9 \cdot 0$.

Certain facts are apparent from this brief résumé: $(a)$ The southern one fourth of the sky is represented, except for the B stars, only to magnitude $5.50 ;(b)$ observations of the fainter northern stars are for the most part of selected lists, chosen with reference to spectral classes, certain limiting magnitudes, large proper motions or other characteristics of special interest; and $(c)$ the data for stars fainter than 7.5 of the later spectral classes are highly selective.

Although there are obvious deficiencies in the present radial velocity material which limit its usefulness for general statistical studies of stellar motions, your Committee is not prepared to propose, as a remedy, a general programme for the systematic determination of the radial velocities of the fainter stars by several observatories, upon a co-operative plan. However advantageous such a plan might appear to be, we are of the opinion that the present procedure, in which each observer selects the stars for his own particular research, will contribute more effectively to the extension of our knowledge of stellar motions. Moreover, this 
method will develop the initiative and originality of the investigator instead of making him a cog in the machine. It would seem that any co-operation that may be desirable in the securing of radial velocity observations should be arranged directly by observers concerned with the particular programme.

It may be confidently assumed that the present deficiencies relating to the faint stars of the later spectral classes will be largely removed in the near future. In the meantime a most valuable set of data will be furnished by the determination of the radial velocities of those stars in the Kapteyn selected areas, for which are also available accurate data concerning their positions, proper motions, apparent magnitudes and distances. The Mt Wilson Observatory is at present engaged upon a programme of this character, but has found it necessary to limit the observations to 436 of the brighter objects. In this field other observatories possessing the necessary equipment conld aid elfectively in extending the data for the motions of the faint stars, without seriously interfering with their own programmes of observation.

There is a most urgent need for radial velocity observations of the fainter stars in the sonthern sky, especially those of Classes $O$ and $B$ and the members of open clusters. We, therefore, suggest that Commission 30 endeavour to find a practicable method of obtaining these observations at an early date. Through the co-operation of the nembers of this Commission it may be possible to arrange to have this work taken up at an existing southern observatory.

Some consideration has been given to the subject of co-operation among observatories in securing observations of spectroscopic binaries, in order to avoid duplication of efforts. The suggestion has been made that there be established a central bureau whose function wonld be to keep observers informed concerning the stars under observation at different institutions. While such a bureau would doubtless render good service in many ways, it would appear to require considerable clerical assistance, at a cost out of proportion to the advantages gained. We are of the opinion that the procedure followed in the past will continue to prove efficient. According to this, each observatory holds itself responsible for deriving the orbits of the binaries discovered by its staff. In case an observer desires to study a spectroscopic binary discovered elsewhere, he should confer with the observatory at which the discovery was made.

$$
\left.\begin{array}{l}
\text { J. H. MOORE } \\
\text { A. H. JoY } \\
\text { W. E. HarPeR }
\end{array}\right\} \text { Sub-Committee }
$$

\section{(b) Report of Sub-Committee on Wave-Lengths}

The terms of reference to the sub-committee were "to study and report upon the problem of replacing the Rowland System of wave-lengths by the International System in all radial velocity determinations and to prepare a corresponding list of wave-lengths for lines observable in stellar spectra of Classes $O, B$ and $A$." Resulting from correspondence and discussion, some progress has been made and the position in regard to wave-lengths for use in radial velocity determinations has been in certain respects clarified.

Although definite instructions were prescribed only for the preparation of tables of wave-lengths on the International System for spectra of Classes $O, B$ and $A$, it was deemed desirable to extend these tables to the later spectral classes if possible. Correspondence was accordingly instituted between the members of the sub- 
committee and also with Dr J. H. Moore, whose valuable suggestions are gratefully acknowledged, towards that end. The results of this correspondence and of discussions among the interested members of the staffs of the four observatories mainly concerned with radial velocities, Mt Wilson, Lick, Yerkes, and Victoria, made it appear of doubtful value at the present time to attempt the preparation of wavelength tables for late type stars.

The principal difficulties arise from the complexity of late type spectra in which many of the best defined lines in single-prism spectra, the highest dispersion that can generally be used in the faint stars remaining to be investigated, are complex blends of two or more components. If these components and their relative intensities remained constant as the temperature decreased, or the effective wave-length remained the same with change of dispersion, the preparation of tables of wavelengths would be relatively simple and such tables would be of very general usefulness. As is well known, neither of these conditions holds and moreover, as will be seen from the main report and from that of the sub-committee on co-operation, the general trend of radial velocity work at the present time is towards the observation of special groups of stars of definite and generally narrowly limited spectral classes and over a small range in magnitude. The effective measured wave-length will obviously vary with the dispersion that can be used and with the spectral class, thus practically entailing the preparation of separate wave-length tables for each individual research. In view of this difficulty and of the fact that late type spectra are frequently measured by the spectro-comparator or by comparison with solar or stellar standards where wave-length tables are not required, the sub-committee are agreed that the publication of general wave-length tables of late type spectra would be of doubtful value.

In the preparation of special wave-length tables an important point has been raised by Adams in regard to the source of the International wave-lengths chosen for the stellar lines, whether the best available laboratory wave-lengths or the Mt Wilson Revised Rowland System should be used as standards. It was pointed out by Adams that the Rowland revised wave-lengths have the advantage of being on a uniform system while laboratory wave-lengths are not necessarily homogeneous and some of them, especially the rarer elements, are not very accurately known. On the other hand the use of the revised Rowland wave-lengths for the stellar lines and laboratory wave-lengths for the comparison lines refers the star to the sun. The sinall displacement there present, of about $+0.5 \mathrm{~km}$. $/ \mathrm{sec}$. between the solar and laboratory wave-lengths, is probably due to the relativity shift and the reference of star to sun eliminates this displacement which is not velocity. While the relativity shift in the sun may be fairly representative of that in the average dwarf star, nothing is known of its amount in the giants or early type stars so that the application of this constant displacement to all stars seems hardly valid. Another objection appears in the wave-length tables appended below of $O$ and $B$ and of $A$ type stars where both stellar and comparison lines are based on laboratory standards, and whose velocities would hence not be homogeneous with those referred to the sun.

It seems necessary, therefore, that some uniform procedure should be adopted in the preparation of the special wave-length tables so that the resulting velocities of all types should be on a homogeneous system. The numerous advantages of the Revised Rowland System for stars of type later than A make its use desirable in preparing wave-length tables of stellar lines. In that case, it is suggested that either the revised Rowland wave-lengths be used for the comparison as well as the stellar lines or, if laboratory wave-lengths are preferred for the comparison lines and 
revised Rowland for the stellar lines, that the small displacement of 0.5 or $0.6 \mathrm{~km} . / \mathrm{sec}$. be applied with the proper sign to the resulting velocities. The radial velocities for all types will then be the actual measured displacements and no correction would be made for relativity or other systematic displacements until some definite knowledge of its magnitude in stars other than the sun becomes available. The sub-committee, therefore, recommends that observers in publishing radial velocity measures either follow the procedure outlined above or else specifically mention that the stellar velocity is referred to the sun and contains the relativity displacement.

The table of wave-lengths of the lines appearing generally in Classes $\mathrm{O}$ and $\mathrm{B}$ and suitable for the measurement of radial velocities is given below. This table is a revision and extension by $\mathrm{J}$. $A$. Pearce, based on the most recent laboratory values, of a table originally compiled by H. H. Plaskett on the International System in I022 for the Class $\mathrm{O}$ stars and extended at Victoria from time to time. The recent valuable paper by $O$. Struve on the lines in Class B spectra hardly requires any additions to this list as the numerous new lines therein contained only appear in exceptional stars or in spectra of high dispersion on fine-grained plates and cannot be used for radial velocity determinations in general.

The table of wavelengths for radial velocity determinations of Class A stars, herewith appended, did not admit of such a direct procedure as in Classes $O$ and $B$, owing to the presence of numerous blends among the metallic lines, and the method adopted by $W$. E. Harper, to whom the table is due, has been partly empirical. All Victoria measures up to the present of the radial velocities of Class A stars, mainly by Harper, have been based on a table compiled by Young $(P u b . D . A . O .2,7)$. This table was formed from the original Rowland wave-lengths although several stellar wave-lengths previously found to give high residuals were arbitrarily readjusted. Although this was later transformed to the Rowland Revised System by application of the correction curve given on page vii, this did not appreciably affect the resulting velocities, which are consequently all on a uniform system.

Four hundred spectra, all measured by Harper, of Classes Ao to Fo with lines both sharp and diffuse in character and on which at least ten lines had been measured were selected for a study of the velocity residuals of each line from the mean of the plate. The mean accidental and systematic residuals, the residuals without and with regard to sign for each line are given in Columns 3 and 4 of the table. Column $\mathrm{I}$ contains the wave-lengths of the star lines used in the Victoria measures, mostly Rowland values transferred to the International System, but with some adjusted wave-lengths as stated above, and Column 2 the number of times the line was measured in the 400 selected plates. Column 3 gives the average residual and Column 5 the correction in wave-length corresponding to the systematic velocity correction of Column 4. Column 6 gives the wave-lengths recommended with explanations, identilications, etc. in the last column. In a few cases, marked by an asterisk, in which there was considerable uncertainty as to the components entering the blend or their relative intensity, the recommended wave-lengths are obtained by directly applying the measured systematic residual. These, at least where more than 30 measures are involved, can, it is believed, be safely used when insufficient unstarred lines are available, though it is considered preferable if possible to use only those in which the identifications are reasonably certain.

It should be remembered that the recommended wave-lengths are the average values obtained from consideration of the residuals from all spectral subdivisions of Class $A$ and from stars with both sharp and diffuse lines. The relative proportion of ionized to neutral a toms will obviously decrease with the temperature and there may 
hence be slight changes in the effective wave-lengths of some of the blended lines. It is believed, however, that the use of these wave-lengths for all subdivisions will not introduce any sensible error in the resulting velocities.

\author{
J. S. Plaskett \\ W. S. ADAMS \\ E. B. Frost
}

Wave-Lengths for Spectral Classes $O$ and $B$

Wave-length
$3933 \cdot 664$
$3964 \cdot 727$
$3968 \cdot 465$
$3970 \cdot 075$
$3994 \cdot 996$
$4026 \cdot 189$
$+4069 \cdot 794$
$4072 \cdot 162$
$4075 \cdot 868$
$4088 \cdot 863$
$4097 \cdot 330$
$4101 \cdot 738$
$4103 \cdot 394$
$4116 \cdot 104$
$4119 \cdot 221$
$4120 \cdot 812$
$4128 \cdot 053$
$4130 \cdot 884$
$4143 \cdot 759$
$+4267 \cdot 16$

r. Primary Standards

\begin{tabular}{|c|c|c|c|c|}
\hline Atom & Authority & Wave-length & Atom & Authority \\
\hline $\mathrm{Ca}$ II & 8 & $4317 \cdot 144$ & O II & 5,6 \\
\hline $\mathrm{HeI}$ & 2 & $4319 \cdot 635$ & O II & 5,6 \\
\hline Ca II & 8 & $4340 \cdot 466$ & $\mathrm{H}$ & 1 \\
\hline $\mathrm{H}$ & 1 & $4349 \cdot 428$ & O 11 & 5,6 \\
\hline$N$ II & 5,6 & 4387.928 & He I & 2 \\
\hline He I & 2 & 4414.904 & O II & 5,6 \\
\hline O II & 5,6 & $4416 \cdot 975$ & O II & 5,6 \\
\hline O II & 5,6 & 4437.549 & He I & 2 \\
\hline O II & 5,6 & $4471 \cdot 477$ & He I & 2 \\
\hline Si IV & 4 & $\$ 4481.228$ & $\mathrm{Mg}$ II & 9 \\
\hline $\mathrm{N}$ III & 5,6 & $4541 \cdot 61$ & He II & 3 \\
\hline $\mathrm{H}$ & 1 & $4552 \cdot 654$ & Si III & 4 \\
\hline N III & 5,6 & $4567 \cdot 872$ & Si III & 4 \\
\hline Si IV & 4 & 4574.777 & Si III & 4 \\
\hline O II & 5,6 & $4590 \cdot 974$ & O II & 5,6 \\
\hline He I & 2 & $4596 \cdot 178$ & O II & 5,6 \\
\hline Si II & 4 & $4685 \cdot 74$ & He II & 3 \\
\hline Si II & 4 & $471.3 \cdot 143$ & He I & 2 \\
\hline He I & 2 & $4861 \cdot 327$ & $\mathrm{H}$ & 1 \\
\hline C II & 7 & $4921 \cdot 929$ & He I & 2 \\
\hline
\end{tabular}

* A blend of $4069 \cdot(336$ (4) and 4069.899 (6), O II. $\dagger$ A blend of 4267.27 (10) and 4267.02 (8), C II. $\ddagger$ A blend of $4481 \cdot 327$ (1) and $4481 \cdot 129$ (1), $\mathrm{Mg}$ II.

$\begin{array}{cl}\text { Wavc-length } & \text { Atom } \\ \mathbf{4 0 0 9 \cdot 2 7} & \text { Hc I } \\ \mathbf{4 1 5 3 \cdot 3 0 4} & \text { O II } \\ \mathbf{4 1 6 8 \cdot 9 7} & \text { He I } \\ \mathbf{4 3 5 1 \cdot 2 7 0} & \text { O II } \\ \mathbf{4 3 7 9 \cdot 1 0 0} & \text { N III } \\ \mathbf{4 5 1 0 \cdot 9 0 6} & \text { N III } \\ \mathbf{4 5 1 4 . 8 6 1} & \text { N III } \\ \mathbf{4 5 2 3 \cdot 5 9} & \text { N III }\end{array}$

II. Secondary Standards

$\begin{array}{ccc}\text { Authority } & \text { Wave-length } & \text { Atom } \\ 12 & 4634 \cdot 145 & \text { N III } \\ 5,6 & 4638 \cdot 857 & \text { O II } \\ 12 & 4640 \cdot 632 & \text { N III } \\ 5,6 & 4641 \cdot 873 & \text { N III } \\ 5,6 & 4649 \cdot 141 & \text { O II } \\ 5,6 & 4650 \cdot 844 & \text { O II } \\ 5,6 & 4651 \cdot 46 & \text { C III } \\ 11 & & \end{array}$

Authority
5,6
5,6
5,6
5,6
5,6
5,6
10

\title{
REFERENCES
}

(I) W. E. Curtis. Roy. Soc. Proc. A, 90, 605, 1914.

(2) P. W. Merrilx. Bull. Bur. Stand. 14, 159, 1917.

(3) F. Paschen. Ann. der Phys. 5o, gor, rgr6.

(4) A. Fowler. Roy. Soc. Phil. Trans, $\Lambda, 225,4$ I, I924.

(5) C. S. Beals. D.A.O. 6, 2 I, I93I.

(6) J. S. Clark. $A p . J .40,332,1914$.

(7) A. Fowler and E. W. H. Selwyn. Roy. Soc. Proc. A, 120, 312, 1928.

(8) H. Crew and G. V. McCauleY. Ap. J. 39, 29, I9I4.

(9) A. Fowler. Roy. Soc. Phil. Trans. A, 214, 225, 1914.

(Io) I. S. Bowen. Phy. Rev. 38, 128, 1931.

(II) A. FowLER. M.N.R.A.S.80, 692, I920.

(12) A. Fowler. Report on Series in Line Spectra, 94, 1922. 


\begin{tabular}{|c|c|c|c|}
\hline & & $\lambda$ & \\
\hline $\mathrm{km}$ & $\lambda$ & mended & Identification and remarks \\
\hline$+2 \cdot 10$ & -.026 & $3 \cdot 664$ & 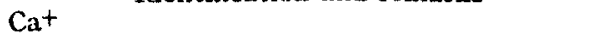 \\
\hline-5.25 & +.070 & $5 \cdot 333 *$ & Fe $\cdot 246$ blended with others \\
\hline$+5 \cdot 12$ & -.069 & $0 \cdot 610$ & $\mathrm{Fe} \cdot 504(3), \mathrm{Ti} \cdot 5 \mathrm{I} 4(6), \mathrm{Mn} \cdot 760(6)$ \\
\hline$+3 \cdot 42$ & -.046 & $5 \cdot 730$ & Fe $132(1)$, Fe $815(8)$ \\
\hline$+4 \cdot 19$ & -.057 & 3.539 & $\mathrm{Fe} \cdot 292(2), \mathrm{Fe} \cdot 60 \mathrm{l}(8)$ \\
\hline$+3 \cdot 84$ & -0.052 & $1 \cdot 687 *$ & Fe $\cdot 743$ probably violet component \\
\hline$-7 \cdot 36$ & -.100 & $7 \cdot(344$ & $\mathrm{La}+.35(1), \mathrm{Y} \cdot 38(1), \mathrm{Sr}^{+} .714(8)$ \\
\hline-0.77 & +011 & 1.738 & Ho \\
\hline+0.94 & -.013 & $8 \cdot 650$ & $\mathrm{Fe} \cdot 549(5), \mathrm{Fe} \cdot 001(2)$ \\
\hline$-4 \cdot 69$ & $+\cdot 065$ & $8 \cdot 053$ & Sit .053 though possibly $\mathrm{V} \cdot 101$ and others \\
\hline-1.57 & +.022 & $0 \cdot 884$ & $\mathrm{Sit} .884$ \\
\hline$+1 \cdot 54$ & $-0 \mathbf{2} \mathbf{1}$ & $3 \cdot 682$ & Fe $-417(5)$, Fe $\cdot 871(7)$ \\
\hline$-6 \times 23$ & +.087 & $8 \cdot 605$ & $\mathrm{Fe} \cdot 239(4), \cdot 331(4), 632(3), 0 \cdot 100(5)$ \\
\hline $\mathbf{3} \cdot \mathbf{6 3}$ & $+\cdot 051$ & $2 \cdot 031$ & Fe 031 main, probably blended with $\mathrm{Fe} \cdot 752$ \\
\hline$-3 \cdot 51$ & $+\cdot 049$ & $5 \cdot 636$ & Fe $\cdot 416(2), \mathrm{Sr}^{+} \cdot 515(10)$, Fe $6 \cdot 186(3)$ \\
\hline$+3 \cdot 02$ & -042 & $6.911 *$ & Fe $\cdot 426, \mathrm{Ca} \cdot 735$, Fe $7 \cdot 435$ blended \\
\hline$-1 \cdot 75$ & +024 & $3 \cdot 275$ & Fe $2 \cdot 729(2), F \mathrm{c}+3 \cdot 164(8)$, Fe $3 \cdot 600(6)$ \\
\hline$-3 \cdot 95$ & +056 & $5 \cdot 902 *$ & Fe .950 main, probably blended with $Y^{+} \cdot 70$ \\
\hline-4.02 & +.057 & $0 \cdot 481$ & Fe $\cdot 131(7)$, Fe $.788(8)$ \\
\hline$-2 \cdot 67$ & +.038 & 0.425 & Fe $9.985(1)$, Fe $0.132(1)$, Fe $0.486(12)$ \\
\hline-3.43 & +.049 & $1 \cdot 548$ & $\mathrm{Fe} \cdot 170(4), \mathrm{Fe} \cdot 764(7)$ \\
\hline+0.17 & -.002 & 9.933 & $\operatorname{Cr} 0.725(5), \mathrm{Ti}+0.230(2)$, Fe $0.380(1)$ \\
\hline-4.87 & +.070 & $7 \cdot 892$ & $\mathrm{Ti}^{+} \cdot 880(8), \mathrm{Fe} \cdot 906(7)$ \\
\hline+6.03 & -087 & $5 \cdot 674^{*}$ & Fe 765 main, but $\mathrm{Sc}^{+} 5.000$ affects blend \\
\hline$-0 \cdot 64$ & +.009 & $0 \cdot 466$ & $\mathrm{H} \gamma$ \\
\hline$-0 \cdot 2 \mathrm{I}$ & +.003 & $1 \cdot 839$ & Cr Fet $.762(5), M g \cdot 916(5)$ \\
\hline+1.21 & -010 & $4.915^{*}$ & Sct $.46(1), Y^{+} .96(5)$ adjusted \\
\hline$+4 \cdot 96$ & -.073 & $5 \cdot 044$ & $\mathrm{Ti}^{+}$ \\
\hline$-1 \cdot 33$ & $+\cdot 020$ & $4 \cdot 752$ & Fe $\cdot 752$ \\
\hline$-1 \cdot 10$ & +016 & $5 \cdot 125$ & $\mathrm{Fe} \cdot 125$, possibly blended with $\mathrm{Sc}^{+} \cdot 55$ \\
\hline-4.85 & +072 & $1 \cdot 310^{*}$ & $\begin{array}{l}\mathrm{Mgt}, \mathrm{Ti} \cdot 26, \mathrm{Mg}+\cdot 33 \text {, latter componer } \\
\text { apparently strongest }\end{array}$ \\
\hline $1 \cdot 1 \cdot 45$ & $\ldots \cdot 022$ & $1 \cdot 270$ & $\mathrm{Tit} \cdot 270$ \\
\hline$-0 \cdot 67$ & +.010 & $8 \cdot 200$ & let .200 \\
\hline-1.90 & +.020 & $5 \cdot 340$ & Fet $\cdot 340$ \\
\hline 0.00 & .000 & $2 \cdot 701$ & Fet $.633(3), \mathrm{Ti} \cdot 802(2)$ \\
\hline$-5 \cdot 52$ & +.083 & $4 \cdot 055^{*}$ & $\mathrm{Ti}+3.97$ main but $\mathrm{Ie}^{+} 4.17$ contributes \\
\hline$-1 \cdot 07$ & +.025 & $9 \cdot 550$ & Fet 48 , Tit 62 assumed equal intensity \\
\hline$-1 \cdot 40$ & +.021 & $1 \cdot 080$ & $\mathrm{Ti}+.980$ \\
\hline$+9 \cdot 69$ & $\cdots \cdot 147$ & $3 \cdot 701 *$ & Fet .841 main but $\mathrm{Ti}^{+} .45$ contributes \\
\hline$-4 \cdot 12$ & +.067 & $1 \cdot 326$ & $\mathbf{H} \beta$ \\
\hline
\end{tabular}

Supplementary list

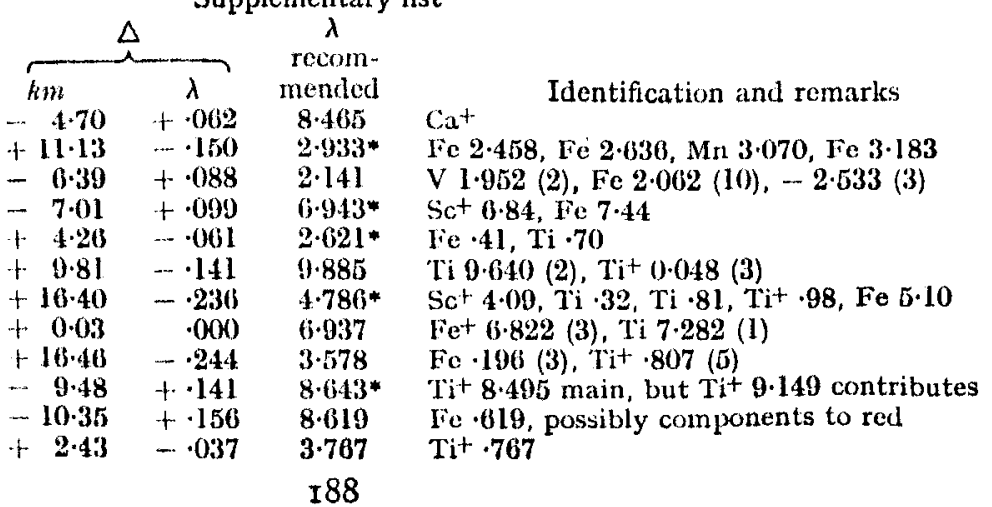




\section{SUMMARY}

A summary of the principal subjects proposed for the consideration of the Commission is herewith appended.

(a) The appointment of a sub-committee to prepare a suitable list of standard velocity stars of fainter magnitudes than those now available and to arrange for obtaining accurate velocities of these stars.

(b) Consideration of the needs for radial velocities of additional southern stars and of a practicable method by which these may be obtained.

(c) Discussion and disposal of the reports of the two sub-committees.

J. S. Plaskett

President of the Commision 